\title{
Characterization of subsurface defects in building envelope and flat roof structure by means of thermography supported by numerical simulation
}

by S. Švaić*, I. Boras*, M. Andrassy* and M. Suša**

${ }^{*}$ Faculty of Mechanical Engineering and Naval Architecture, University of Zagreb, Croatia

${ }^{*}$ Department of Electrical and Computer Engineering, Université Laval, Quebec, Canada

Key words:

subsurface defects, building, numerical simulation, measurement

Abstract

Infrared thermography can be successfully applied as thermal non-destructive method for determination and characterization of subsurface defects in building envelope or flat roof structure.

The paper presents comparison of quantitative results obtained by numerical simulation and thermographic measurements. The advantage of numerical simulation is in its possibility to give results for different wall and roof structure exposed to various start and boundary conditions. On figure 1 the various facade damages like delamination and fall of plaster, and adequate temperature response recorded by infrared camera are presented.
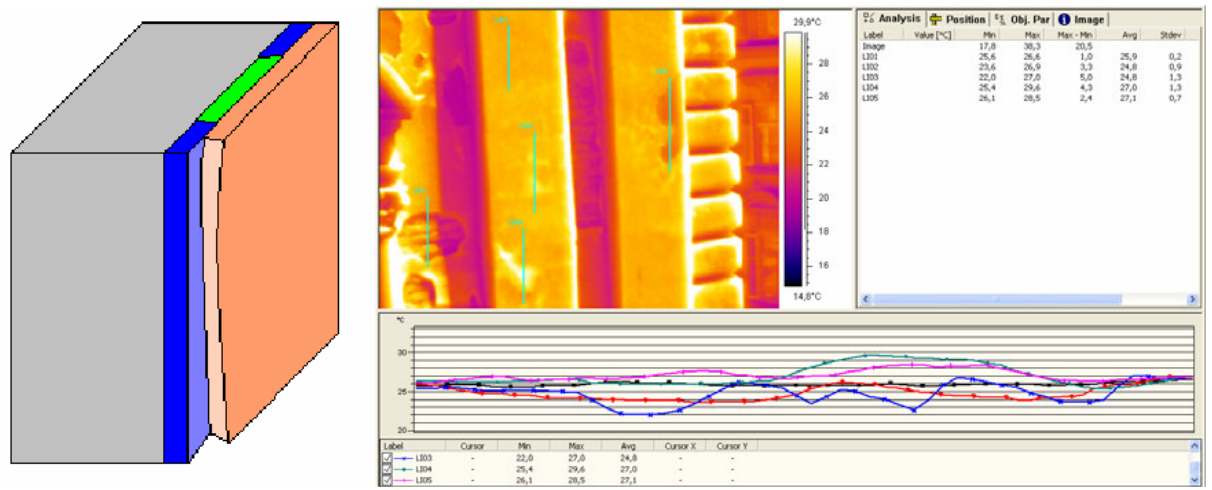

Figure 1. Left: the various facade damages; right: result of measurement - thermogram

The damages in roof structure in the form of air and water spots and corresponding thermogram are shown on figure 2.
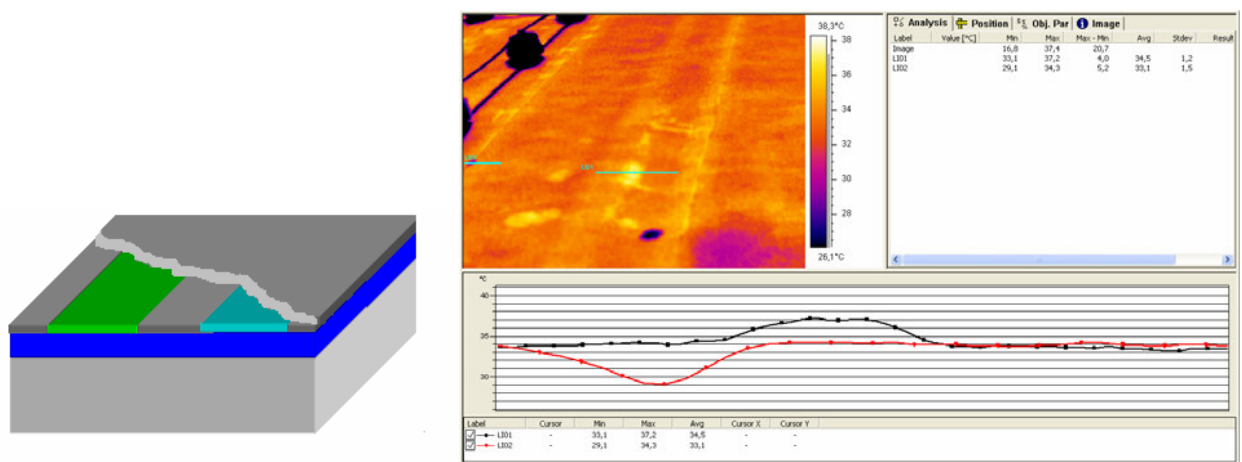

Figure 2. Left: The damages in roof structure; right: result of measurement - thermogram

The applied numerical model is based on the control volume method. Numerical simulation of heat transport process proves not only the results of thermographic measurement but also can be a tool for analyzing the behavior of various structures in different circumstances. 
http://dx.doi.org/10.21611/qirt.2008.05_06_08 